\title{
Еныгин Д.В.
}

Российский экономический университет имени Г. В. Плеханова, г. Москва, Россия

E-mail: yenygen@gmail.com

\section{РОЛЬ БИЗНЕС-ИНКУБАТОРА В ПРОФЕССИОНАЛЬНОЙ ПОДГОТОВКЕ БУДУЩЕГО ЭКОНОМИСТА В МУЛЬТИКУЛЬТУРНОЙ ОБРАЗОВАТЕЛЬНОЙ СРЕДЕ}

\author{
D.V. Enygin \\ Plekhanov Russian University of Economics, Moscow, Russia \\ E-mail: yenygen@gmail.com \section{IN THE PROFESSIONAL TRAINING OF THE FUTURE ECONOMISTS IN THE MULTICULTURAL EDUCATIONAL ENVIRONMENT} \\ THE ROLE OF THE BUSINESS INCUBATOR
}

\begin{abstract}
В современном мире вопросы мультикультурного образования приобретают особую важность, ввиду ряда цивилизационных процессов, протекающих сейчас в нашем обществе. Особый акцент в связи с этим приобретает профессиональная подготовка будущего экономиста к работе в мультикультурной среде.

Сегодня многие ведущие вузы нашей страны в своей структуре создают бизнес-инкубаторы, которые и являются элементом указанной мультикультурной образовательной среды, а также продуктивным средством развития широкого спектра профессиональных умений будущих экономистов.

Одной из основных задач современного университетского бизнес-инкубатора является учет культурного разнообразия студентов, сотрудников и выявление преимуществ их межкультурного взаимодействия.
\end{abstract}

Ключевые слова: бизнес-инкубатор, иноязычная профессиональная подготовка, мультикультурное образование, профессиональная подготовка будущего экономиста.

In the modern world, the issues of multicultural education are of particular importance, taking into account civilizational processes happening now in our society. A special emphasis in this regard is made on the professional training of the future economists for work in the multicultural environment.

Today many leading universities of our country create business incubators in their structure, which are an element of this multicultural educational environment, as well as a productive tool for developing a wide range of professional skills of future economists.

One of the main tasks of the modern university business incubator is to take into account the cultural diversity of students and employees and to identify the advantages of their intercultural interaction.

Key words: business incubator, foreign language professional training, multicultural education, professional training of the future economist.

В современном мире мы все чаще сталкиваемся с необходимостью межкультурного взаимодействия в нашей профессиональной сфере, ввиду наличия огромного количества зарубежных партнеров и коллег. Особенно актуальным это становится для специалистов экономического профиля, так как им приходится сталкиваться с иностранными коллегами сразу в нескольких направлениях: деловые переговоры, профессиональная переписка, питчинг, мультинациональные тимбилдинги и т. д. Все это выдвигает требование не только к владению иностранным языком на высоком уровне, но и к сформированности ряда мультикультурных умений (толерантность, принятие, межкультурная эмпатия), а также к наличию комплекса знаний о соответствующих культурах, что по- зволяет сотрудничеству на глобальном уровне быть продуктивным.

Многие ученые [1]-[9] подтверждают, что наиболее эффективно вышеупомянутые умения и навыки формируются в процессе погружения в мультикультурную образовательную среду, под которой мы понимаем актуальный иерархический пространственно-временной континуум, в котором нелинейным способом взаимодействуют различные этнические и мировые педагогические явления, культурные традиции и образовательные практики с целью всестороннего планетарного (глобального) становления и развития современной личности на позициях толерантности, взаимного интереса, уважения и эмпатии.

Проектируя мультикультурную образовательную среду в целом профессиональной под- 
готовки будущего экономиста, следует учесть совершенно все элементы окружающей действительности студента, так как они оказывают непосредственное влияние на формирование его профессиональных качеств и компетенций. Одним из направлений проведенного анализа университетской среды в рамках данного исследования было инновационное, результатом которого стал факт возникновения определенного количества новаторских элементов в виде бизнес-инкубаторов в вузах нашей страны.

Проанализируем понятие бизнес-инкубатора. По мнению Афанасьевой Л.А. [1], основной целью данного предприятия является помочь на начальном этапе открывающему свое дело. Ученая характеризует термин «инкубирование» как комплекс условий, способствующих развитию молодых компаний. В практическом повседневном смысле бизнес-инкубатор представляет собой организацию, обеспечивающую начинающего предпринимателя помещением, необходимым оборудованием, оргтехникой, средствами связи, рядом консалтинговых услуг с целью его качественного и всесторонего развития в коммерческом мире. Отметим, что первые бизнес-инкубаторы зафиксированы еще в 1950 году в Великобритании, а после 83-го их широкое распространение пришлось на США.

Отдельно следует выделить бизнес инкубаторы [10], организованные при высших учебных заведениях, так как они становятся мощнейшим инструментом кардинальных перемен в становлении будущего специалиста, потому что сама идея пересмотра роли современного студента выступает колоссальным мотиватором, ведь после возникновения университетского бизнес инкубирования в нашей стране именно студент выступает прообразом отечественной инновационной экономики, это более не объект, конспектирущий лекции, выступающий на семинарах и коллоквиумах, а самостоятельная деловая единица, принимающая участие в развитии себя и своей страны. Помимо базовой коммерческой основы, бизнес-инкубатор начинает выступать средой формирования успешного представителя нашей культуры - такие студенты носят элитный статус и играют роль определенных эталонных моделей для студентов экономического профиля.

На современном этапе развития образования изменилась и роль вуза. Это более не простран- ство учебы, а место развития новаторских идей в определенной сфере в зависимости от профиля. Университет сегодня - это инновационная площадка, которая постоянно находится в активном поиске новых идей и методологии их внедрения как средства формирования профессиональной компетенции будущего выпускника [11].

Именно поэтому бизнес-инкубатор непосредственно является элементом среды профессиональной подготовки будущего специалиста в целом, и его иноязычной профессиональной подготовки в частности.

Особый акцент следует сделать на роли данной структуры как элемента мультикультурной образовательной среды. Отметим, что на сегодняшний момент диверсификация человеческих ресурсов является одной из актуальных междисциплинарных проблем. Суть указанной теории заключается в необходимости учета различий между людьми в организации. К данным различиям относят расу, пол, этническую группу, возраст, личность, когнитивный стиль, владение жильем, организационную функцию, образование, фоновые знания и многое другое. Весь указанный комплекс охватывает не только то, как люди воспринимают себя, но и то, как они воспринимают других. Это восприятие влияет на их взаимодействие. Современные успешные организации признают необходимость немедленных действий и готовы инвестировать ресурсы на управление разнообразием на рабочем месте. Более того, сегодня ученые признают как факт, что успех и конкурентоспособность организации зависят от ее способности охватить разнообразие и реализовать это как преимущество. Доказано, что организации, использующие разнообразие людей, могут предлагать более продуктивные решения проблем в сфере обслуживания, поиска и распределения ресурсов. Сотрудники из разных социальных и культурных сфер привносят индивидуальные таланты и опыт, предлагая идеи, которые гибки в адаптации к колебаниям современных требований. Принимая во внимание цель данной статьи, отметим, что диверсификацию в целом рассматриваем в аспекте культурных различий [12].

Следовательно культурное разнообразие людей предполагает многообразие навыков и опыта (например, мультилингвальность - владение несколькими языками, культурное понимание), что 
позволяет любой организации стать успешнее в глобальном смысле и выйти на мировой уровень. Именно поэтому многие бизнес-инкубаторы при университетах сегодня уделяют должное внимание диверсификации персонала, чему способствует и совершенно разнообразный контингент студентов (представители различных национальностей, проживающие на территории отдельного региона, студенты по обмену из других стран в рамках международных программ). Участники университетских бизнес-инкубаторов, благодаря учету вышеуказанных принципов, достигают гораздо более максимальных результатов за счет комфортного обмена различными точками зрения, что обеспечивает больший набор идей и опыта. Такие бизнес-инкубаторы воодушевляют всех своих сотрудников реализовать свои самые высокие способности [13].

Еще более инновационной идеей в современных инкубаторах становится особый акцент на владении иностранным языком как средством получения профессиональных знаний. Высокий уровень английского, например, позволяет участнику указанной структуры быть более эффективным и производительным за счет прослушивания лекций западных бизнес-гуру на языке оригинала или путем участия в международных фестивалях бизнес идей и т. д. При ряде отечественных инкубаторов регулярно проводятся лекции на иностранном языке по практическим основам бизнеса, ряд профессиональноориентированных терминов, необходимых будущему специалисту экономического профиля, носит также иноязычной характер (например ROI и т. п.). Данные позиции подтверждают роль бизнес-инкубатора как среды иноязычного и мультикультурного профессионального развития специалиста [14].

Тем не менее, в работе бизнес-инкубаторов в аспекте мультикультурного иноязычного развития студентам присутствует и огромное количество сложностей. Рассмотрим основные из них [15].

Первой здесь выступает линейка трудностей, появляющихся в процессе коммуникации, так как студенту необходимо преодолеть перцепционные, культурные и языковые барьеры для успешной реализации себя. Неэффективное общение в рамках ключевых задач приводит к путанице, отсутствию командной работы и низкому моральному духу.
Есть и определенные сложности в устойчивость к изменениям - всегда есть студенты, которые откажутся признать тот факт, что социальный и культурный состав их рабочего места (бизнес-инкубатора в данном случае) меняется и что это приносит больше возможностей, чем проблем. Устаревший менталитет замалчивает новые идеи и тормозит прогресс, несмотря на то, что студенты должны были бы создавать и внедрять в рамках работы в бизнес-инкубаторе индивидуальную стратегию, чтобы максимально использовать влияние разнообразия для своего конкретного проекта.

Исходя из этого, можно охарактеризовать ряд рекомендаций для бизнес-инкубаторов по развитию технологий мультикультурного образования в своей деятельности. В связи с этим выделим несколько направлений деятельности:

Оценка культурного разнообразия в составе студентов. Это должно стать неотъемлемой частью системы управления, что может помочь команде определить, какие проблемы и препятствия для разнообразия присутствуют в бизнесинкубаторе, и какие политики необходимо добавить или устранить.

Развитие культурного разнообразия - ключевое решение. Наиболее продуктивным здесь станет разработка плана мероприятий, направленных на развитие профессиональных мультикультурных умений участников бизнесинкубатора.

Внедрение культурного разнообразия в плане сотрудников бизнес-инкубатора. Политика разнообразия должна быть включена во все аспекты функций и цели организации. Отношение к разнообразию происходит по вектору «сверху вниз» (от руководства к рядовым сотрудникам. Студенты, работая с наставниками, которые являются представителями различных культур, значительно выиграют за счет приобретения опыта работы в многонациональном коллективе, применения более разнообразного репертуара бизнес технологий в своей деятельности. Более того, такие студенты получат уникальную возможность развить личный уровень толерантности, принятия и глобального планетарного мышления.

Таким образом, можно сделать вывод о том, что университетский бизнес-инкубатор являет- 
ся продуктивной платформой для развития иноязычных профессиональных умений будущих экономистов как элемент мультикультурной образовательной среды, при условии должного внимания к формированию умений межкультурного взаимодействия студентов.

12.12.2017

\section{Список литературы:}

1. Афанасьева, Л.А. Что такое бизнес-инкубатор? / Л.А. Афанасьева // Современное развитие экономических и правовых отношений. Образование и образовательная деятельность. - 2014. - №.1. - С. 7-10.

2. Журавлев, В.А. Классический исследовательский университет: концепция, признаки, региональная миссия / В.А. Журавлев // Университетское управление: практика и анализ. - 2000. - №2 (13). - С. 25-31.

3. Булавенко, О.А. Сущностные характеристики профессиональной компетентности современного специалиста / О.А. Булавенко, В.И. Миханев // Ученые записки Комсомольского-на-Амуре государственного технического университета. - 2010. - Т. 2. №1. - C. 23-28.

4. Лавриков, Ю.А. О модели профессиональной подготовки экономиста / Ю.А. Лавриков // Улучшение подготовки экономистов и экономической подготовки инженеров. - 1973. - С. 19.

5. Bøllingtoft, A. The networked business incubator-leveraging entrepreneurial agency? / A. Bøllingtoft, J.P. Ulhøi // Journal of business venturing. -2005 . - T. 20. - №2. - C. 265-290.

6. Mian, S.A. Assessing and managing the university technology business incubator: an integrative framework / S.A. Mian //Journal of business venturing. - 1997. - T. 12. - №4. - C. 251-285.

7. DiTomaso, N. Workforce diversity and inequality: Power, status, and numbers / N. DiTomaso, C. Post, R. Parks-Yancy // Annu. Rev. Sociol. - 2007. - T. 33. - C. 473-501.

8. Allen, D.N. Business incubator life cycles / D.N. Allen // Economic Development Quarterly. - 1988. - T. 2. - №1 . - C. 19-29.

9. Schneider, S.K. Three social dilemmas of workforce diversity in organizations: A social identity perspective / S.K. Schneider, G.B. Northcraft // Human Relations. - 1999. - T. 52. - №11. - C. 1445-1467.

10. Cooper, C.E. Motivations and obstacles to networking in a university business incubator / C.E. Cooper, S.A. Hamel, S.L. Connaughton // The Journal of Technology Transfer. - 2012. - T. 37. - №4. - C. 433-453.

11. Bergek, A. Incubator best practice: A framework / A. Bergek, C. Norrman // Technovation. - 2008. - T. 28. - №1-2. - C. 20-28.

12. Bendick Jr, M. Workforce diversity training: From anti-discrimination compliance to organizational development / M. Bendick Jr, M.L. Egan, S.M. Lofhjelm // People and Strategy. - 2001. - T. 24. - №2. - C. 10.

13. Education, training and the global economy / Ashton D. N. et al. - Cheltenham : Edward Elgar, 1996. - C. 100-104.

14. Lasswell, H.D. Legal education and public policy: Professional training in the public interest / H.D. Lasswell, M.S. McDougal // The Yale Law Journal. - 1943. - T. 52. - №2. - C. 203-295.

15. A model for managing workforce diversity // Management Education and Development. - 1990. - T. 21 . - №4. - C. 321 -326.

\section{References:}

1. Afanasyeva L. A. What is a business incubator? Sovremennoe razvitie ehkonomicheskih i pravovyh otnoshenij. Obrazovanie i obrazovatel'naya deyatel'nost' [Modern development of economic and legal relations. Education and educational activities], 2014, no.1, pp. 7-10.

2. Zhuravlev V. A. Classical research university: concept, signs, regional mission Universitetskoe upravlenie: praktika i analiz [University management: practice and analysis], 2000, №2 (13), no. 13. pp. 25-31.

3. Bulavenko O.A., Mikhanev V. I. Essential characteristics of professional competence of a modern specialist Uchenye zapiski Komsomol'skogona-Amure gosudarstvennogo tekhnicheskogo universiteta [Scientific memories Komsomolsky-na-Amure state technical university], 2010, vol. 2, no. 1, pp. 23-28.

4. Lavrikov Yu.A. About the model of professional training of the economist Uluchshenie podgotovki ehkonomistov i ehkonomicheskoj podgotovki inzhenerov [Improving the training of economists and economic training of engineers], 1973, p. 19.

5. Bøllingtoft A., Ulhøi J. P. The networked business incubator-leveraging entrepreneurial agency? Journal of business venturing, 2005, vol. 20, no 2, pp. 265-290.

6. Mian S.A. Assessing and managing the university technology business incubator: an integrative framework. Journal of business venturing, 1997, vol. 12, no. 4, pp. 251-285.

7. DiTomaso N., Post C., Parks-Yancy R. Workforce diversity and inequality: Power, status, and numbers. Annu. Rev. Sociol., 2007, vol. 33, pp. $473-501$.

8. Allen D.N. Business incubator life cycles. Economic Development Ouarterly, 1988, vol. 2, no. 1, pp. 19-29.

9. Schneider S.K., Northcraft G.B. Three social dilemmas of workforce diversity in organizations: A social identity perspective. Human Relations, 1999, vol. 52, no. 11, pp. 1445-1467.

10. Cooper C.E., Hamel S.A., Connaughton S.L. Motivations and obstacles to networking in a university business incubator. The Journal of Technology Transfer, 2012, vol. 37, no. 4, pp. 433-453.

11. Bergek A., Norrman C. Incubator best practice: A framework. Technovation, 2008, vol. 28, no. 1-2, pp. 20-28.

12. Bendick Jr M., Egan M. L., Lofhjelm S. M. Workforce diversity training: From anti-discrimination compliance to organizational development. People and Strategy, 2001, vol. 24, no. 2, p. 10.

13. Ashton D.N. et al. Education, training and the global economy. Cheltenham : Edward Elgar, 1996, pp. 100-104.

14. Lasswell H.D., McDougal M.S. Legal education and public policy: Professional training in the public interest. The Yale Law Journal, 1943, vol. 52 , no. 2, pp. 203-295.

15. Bartz D.E. et al. A model for managing workforce diversity. Management Education and Development, 1990, vol. 21, no. 4, pp. $321-326$.

\section{Сведения об авторе:}

Еныгин Дмитрий Викторович, доцент кафедры иностранных языков №1

Российского экономического университета имени Г.В. Плеханова, кандидат педагогических наук

E-mail: yenygen@gmail.com

117997, г. Москва, пер. Стремянный, д. 36, корп. 3, каб. 301, 618 